\title{
Archimedean screw as fish-friendly turbines for harnessing hydropower potential
}

\author{
Cristian Purece ${ }^{1 *}$, and Lilica Corlan ${ }^{1}$ \\ ${ }^{1}$ INCDE ICEMENERG, Bucharest, Romania
}

\begin{abstract}
Hydraulic energy is one of the most important sources of renewable energy today. It is also a complementary source to other renewable energy sources, being the only one that offers an important nonpolluting storage capacity (through pump storage facilities). Another essential quality of hydraulic energy is its ability to regulate the energy system to allow the integration of other sources, in which the process of generating energy depends on factors that cannot be controlled (sun, wind, etc.). However, hydropower plants can damage ecosystems, especially by affecting fish within their turbines. Usually, fish cannot pass unharmed through most of the turbines. The main exceptions generally include some low head (below $8 \mathrm{~m}$ ) turbines, such as the Very Low Head (VLH) turbine and the screw turbine, but lately strategies have also been developed for high head hydropower plants such as: fish passage facilities and fish friendly turbines such as Alden turbine, Minimal Gap Runner turbine (MGR). However, this article only deals with screw-type turbines, lowhead fish-friendly turbines and how to implement them in order to obtain sustainable green energy.
\end{abstract}

\section{Introduction}

Sustainable green energy production is one of the main global challenges today. Increasing $\mathrm{CO}_{2}$ emissions, environmental pollution and global warming are leading researchers around the world to find new energy resources [1]. Renewable energies such as solar, wind, geothermal and hydropower, as popular types of renewable energy resources, can be found all over the world [2]. Among these resources, hydropower is widely used as high-head hydropower plants. Although almost all high power hydropower opportunities have been largely depleted, there is a strong potential for low head hydropower resources (small hydropower) potential to be exploited. Some of these resources are small rivers, irrigation systems, drinking water networks, wastewater networks, cooling systems, etc. In hydropower plants, the hydraulic power of water is converted into mechanical power using a turbine and then in electricity with a generator.

Recently, the reverse use of the conventional Archimedes screw pump is considered a popular technology to be used as a turbine to generate electricity from running water, called the Archimedes screw turbine. Traditionally, the Archimedes screw has been used to pump

* Corresponding author: cristianicemenerg@yahoo.com 
water from a lower level to a higher level or to transport liquid or solid materials in a horizontal or inclined plane [3].

Currently there are different types of turbines for electricity generation, including Kaplan, Francis, Pelton type turbines, etc. Comparing the relative costs of an Archimedes screw turbine and a Kaplan turbine, a common turbine for a low head hydropower site, it was found that for an energy production of about 15\% more, for an Archimedes screw turbine the cost is about $10 \%$ lower, and the annual cost capital is $22 \%$ cheaper [4]. In addition, Archimedes' screw turbine is an ecological and fish-friendly structure, it needs little civil works for installation, it can be installed even in existing structures [5].

From previous researches it can be seen that the efficiency of the screws decreases when the rotational speed increases, as the frictional forces become unexpectedly high [6]. Numerical researches on the actual performance of Archimedes screw turbine are limited. The main objectives of this paper are to perform numerical simulations to determine the performance of Archimedes screw turbines according to different parameters as well as the presentation of an example of implementation of Archimedes screw turbines.

\section{Theoretical basis}

It is generally assumed that the weight of water passing through the screw's blades drives the screw [7]. Assuming no losses, all potential energy contained in the water flow can be extracted, giving such a turbine maximum theoretical efficiency. However, most of the weight of the water in the Archimedean screw rests on the trough, which does not move (Figure 1). The power is equal to the force multiplied by velocity and, since the screw rotation speed vector acts tangentially on the screw, only a small part of the water weight (the part acting on the inclined outer section of the blade) contributes to the conversion of hydraulic energy into mechanical energy. Therefore, the contribution of gravity can be neglected.

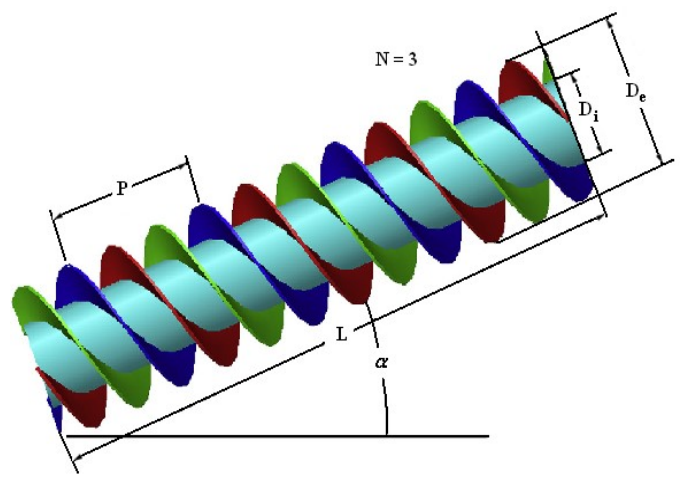

Fig. 1. The Archimedean screw [2]

We consider that the screw turbine has a head difference $H$, a screw length $L$, an inside diameter $D_{\mathrm{i}}$, an outside diameter $D_{\mathrm{e}}$, a pitch $P$, a number of blade $N$, a turns of the helix $m$, a slope $\alpha$ angle between the screw shaft and the horizontal. The longitudinal section of Figure 2 (let) shows the water level inside the screw; there is a difference in head between two blades, so that a horizontal hydrostatic force is developed. Figure 2 (right) indicates the hydrostatic pressure/force on inclined blades, with an upstream pressure higher than the downstream pressure acting normally on the blades. However, only the component in the direction of rotation of the screw will contribute to the rotation of the screw turbine blades. 

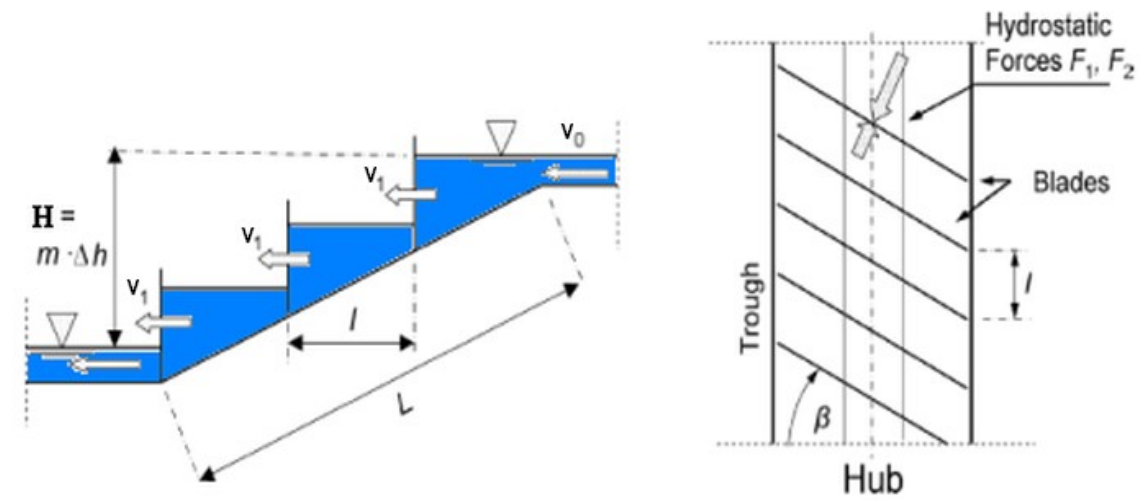

Fig. 2. Archimedean screw: longitudinal section (left), plan view of submerged blade (right)

A detailed view of a blade of Archimedes' screw is shown in Figure 3. The difference in water level between the ascending and descending parts of each blade produces a hydraulic force, $F_{h y d}$, which moves the screw with a velocity $v_{l}$, generating a power $P_{\text {blades }}=$ $F_{\text {hyd }} \times v_{l}$. With an angle $\alpha$ between the screw shaft and the horizontal and a distance $l$ between two individual blades, the water depth increases by:

$$
\Delta h=l \tan \alpha=(L / m) \tan \alpha \text { or } \Delta h=H / m
$$

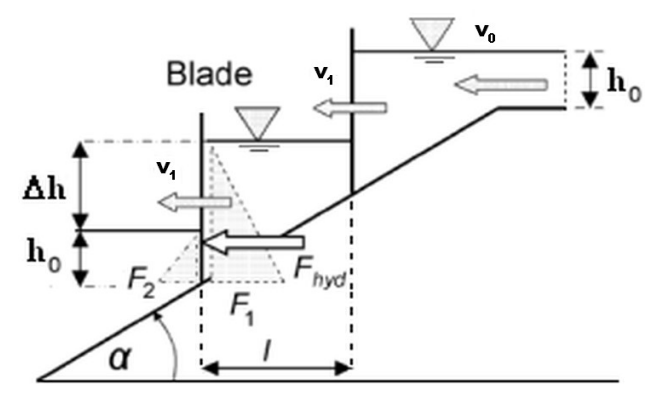

Fig. 3. Hydraulic forces acting on the screw blades relation:

The specific hydraulic energy $(E)$ changed in the hydraulic turbine is defined by the

$$
E=g \cdot H=\frac{\left(p_{1}-p_{2}\right)}{\rho}+\frac{v_{1}^{2}-v_{2}^{2}}{2}+g \cdot\left(z_{1}-z_{2}\right)
$$

where: $H$ is the head or load available between the high pressure and the low pressure reference section of the hydraulic turbine, and $g$ is the gravitational acceleration, $\rho$ is the density of water, $P_{1}$ is the pressure in the high pressure reference section, $P_{2}$ is the pressure in the low pressure reference section, $v_{1}$ is the velocity in the high pressure reference section, $v_{2}$ is the velocity in the low pressure reference section.

In hydraulic turbines that convert only position-specific potential energy, equation (2) is reduced to the expression: $E=g\left(z_{1}-z_{2}\right)$ and the degree of reaction is zero, because the pressure is constant and equal to that of the atmosphere $\left(p_{1}=p_{2}=p_{a t}\right)$, and the velocities in reference sections 1 and 2 are negligible, or have quasi-equal values, so the kinetic term in 
equation (2) is cancelled, $\left(\frac{v_{1}^{2}-v_{2}^{2}}{2}\right) \equiv 0$. This category includes elevators (for example,

Archimedes' screw turbine), gravitational water wheels, and hydraulic transformers for pumping used in antiquity (made by coupling a water wheel and an elevator) [8].

The mechanical energy produced by the rotation of the screw is transformed into electrical energy using a generator. The power supplied to the generator terminals is given by the following equation:

$$
P=\eta \rho g H Q
$$

and the hydraulic power is:

$$
P_{h i d}=\rho g H Q
$$

where $\eta$ is the efficiency of the hydro unit (turbine + generator), $H$ is the head of the turbine, $Q$ is the turbine flow [9].

Therefore, the higher will be the head turbine and the flow rate is, the higher will be the power generated by it. In order to obtain a very high energy, the head of the turbine should be increased to a substantial height by making a dam, but such a task is difficult to accomplish, it takes more time and a lot of money should be invested. Thus, hydropower plants should be without an accumulation basin or have a very small head. The Archimedes screw turbine can be used in such places with low head.

For the Archimedes screw turbine the head $H$ can be written as:

$$
H=m \Delta h
$$
relation:

The mechanical power $P_{\text {mec }}$ of the Archimedes screw turbine can be calculated by the

$$
P_{\text {mec }}=T \omega=T(2 \pi n / 60)
$$

where: $T$ is the torque, $\omega$ is the angular velocity, $n$ is the turbine rotational speed.

The efficiency of the turbine $\eta_{T b}$ can be calculated with the relationship:

$$
\eta_{T b}=\frac{P_{m e c}}{P_{h i d}}
$$

\section{Calculation of screw turbine parameters}

Numerical simulation was used to perform the calculation. The simulation of the Archimedes screw turbine model was performed using ANSYS FLUENT, Computational Fluid Dynamics (CFD) [10]. This method is important for industrial applications, the main advantage of using this technique is that it reduces the time and cost of design for industrial applications. By using this technique a reduction of the design cost is obtained by $40 \%$ compared to the experimental methods. The basic equations of this technique are the Navier Stokes equations, developed by Claude Louis Navier [11].

To model the fluid through the Archimedes screw turbine before applying the conventional Navier-Stokes equation there are necessary assumptions required. These assumptions are: fluid is in single phase; water is considered as incompressible fluid; properties of water are temperature independent. Numerical method used is the method of Reynolds-averaged Navier-Stokes equations (RANS). 
The parameters of the Archimedes' turbine screw for which the numerical simulation was performed were: screw length $L=1000 \mathrm{~mm}$, outer diameter $D_{e}=130 \mathrm{~mm}$, inner diameter $D_{i}=70 \mathrm{~mm}$, number of blades $N=1$, pitch $P=70 \mathrm{~mm}$, trough diameter $D t=134$ $\mathrm{mm}$, slope $\alpha=30^{\circ}, 35^{\circ}, 40^{\circ}, 45^{\circ}$, nominal turbine flow $Q=2.5 \mathrm{l} / \mathrm{s}$.

The transient flow state was used in simulation as its boundary condition. The upstream water velocity (inlet) as well as the rotational speed of the of turbine screw, were taken from the experimental results, and the pressure at downstream (outlet) is equal to 0 .

In order to obtain a good accuracy, a non-uniform grid was chosen. Convergence criteria were set to less than $\left(10^{-6}\right)$ for continuity and momentum residuals. It has been used a number of iterations 100. After study, it was found that the best value for the size of the element is $5 \mathrm{~mm}$, the large values from $5 \mathrm{~mm}$ did not give accurate results, and at small values from $5 \mathrm{~mm}$, the results did not change, it was observed only an increase of the time of the analysis.

The results obtained from the numerical calculation are presented in Figures 4 - 9 . Figure 4 shows the relationship between the mechanical power of the turbine and the flow.

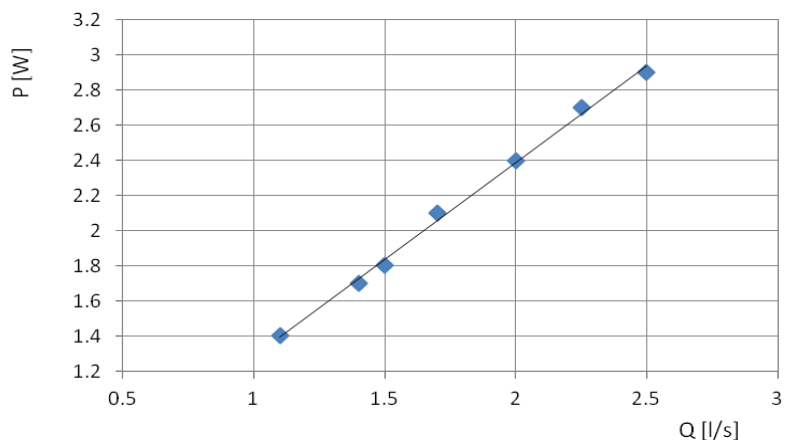

Fig. 4. The relation between flow rate and mechanical power

From the curve in Figure 4 it can be seen the increase of the mechanical power with the increase of the flow. The reason for the increase in mechanical power is that the flow increases the force acting on the blades and thus increases the rotation of the blade, which leads to increased mechanical power.

The relationship between flow and efficiency at an angle of inclination of Archimedes' screw of $35^{\circ}$ is given in Figure 5. As the flow rate increases, the efficiency of the Archimedes screw increases until it reaches the maximum value corresponding to the optimal flow rate and then begins to decrease. This means that in order to obtain a high efficiency, the optimal flow must be found.

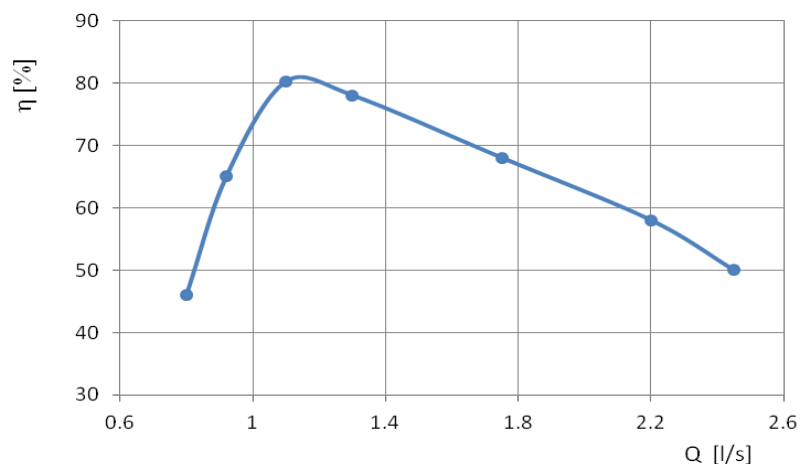

Fig. 5. The relation between efficiency and flow rate $\left(35^{\circ}\right.$ Angle $)$ 
From Figure 6 it can be seen that as the flow rate increases, the rotational speed increases at each angle of inclination of the Archimedes screw axis $(\alpha)$, but when the value of the angle increases, the lines of rotation speed converge, which means that the change in rotation speed becomes small, this is due to the existence of energy losses caused by overflow.

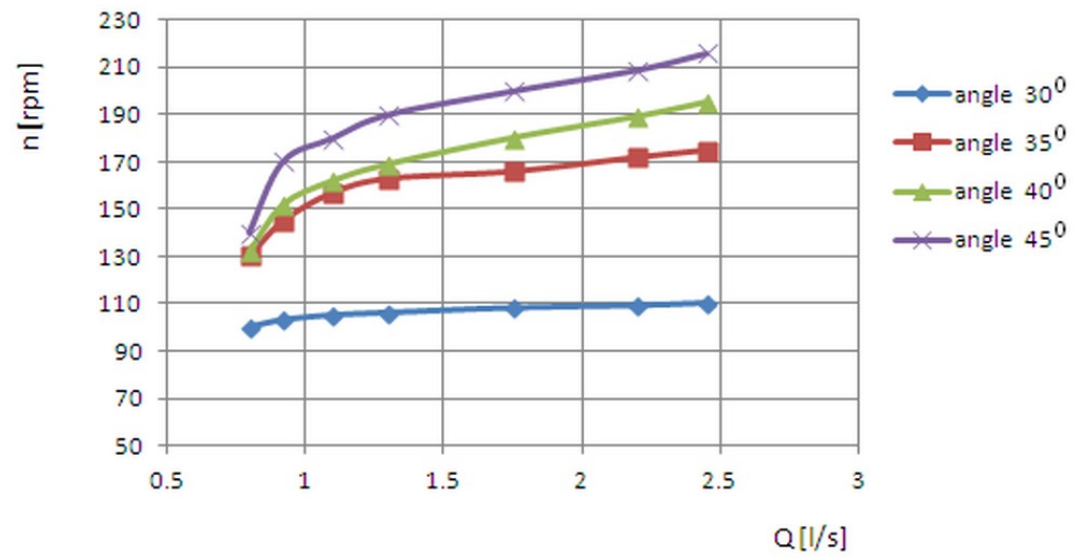

Fig. 6. Variation of the rotation speed and flow rate for different angles $\alpha$

From the obtained results it was concluded that the optimal angle $\alpha$ between the turbine axis and the horizontal is the angle of $35^{\circ}$. Figure 7 shows the relationship between efficiency and rotational speed for an angle of inclination of $35^{\circ}$ between the screw turbine and the horizontal. We notice that the efficiency at the beginning increases with the increase of the rotation speed until it reaches the maximum value $80.2 \%$, at a rotation speed of $157 \mathrm{rpm}$, after which the efficiency begins to decrease with the increase of the rotation speed.

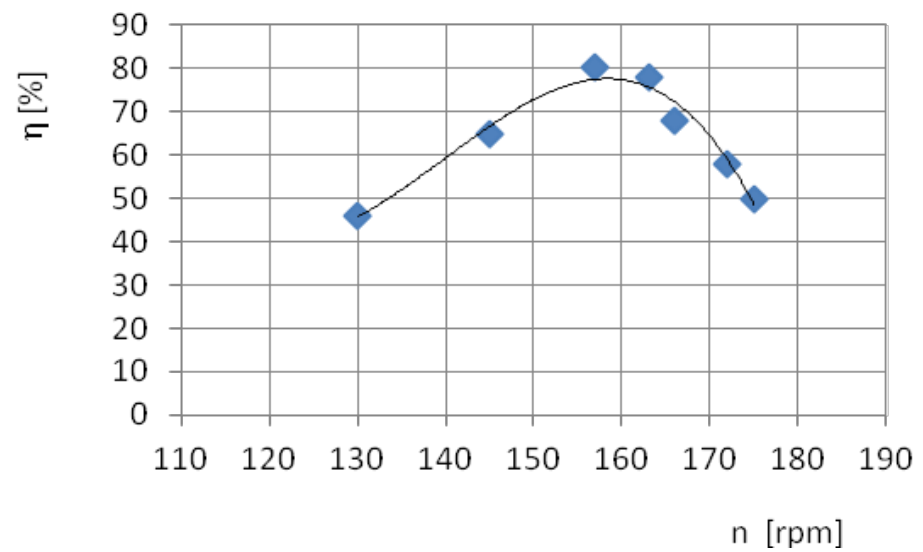

Fig. 7. The relation between efficiency and rotation speed $\left(35^{\circ}\right.$ Angle $)$

The relationship between the torque of the screw turbine and the number of blades is shown in Figure 8 . The higher the number of blades, the torque will increase, due to the increase of the water contact area with the blades, but with the continuous increase of the number of blades, the difference between the torque values becomes small, therefore you can choose the optimal number of blades, but with the larger the number of blades, the manufacturing process becomes more complicated and expensive. 


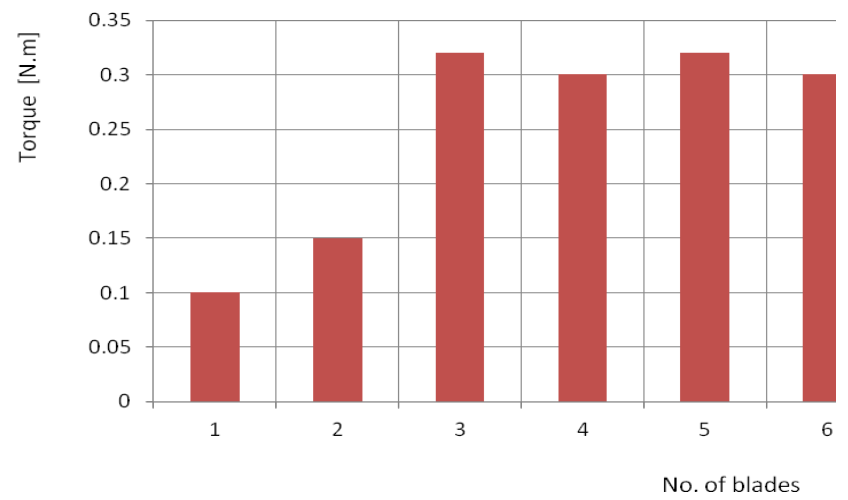

Fig. 8. The relation between torque and number of blades

Figure 9 shows the relationship between turbine efficiency and the number of blades for an Archimedes screw turbine. From the Figure 9, we notice that if the number of turbine blades is higher, the turbine efficiency is higher, and this is due to the higher number of blades, because of the larger contact surface with the turbine water, the couple will also increase. However, the increase in efficiency becomes small or oscillating if the number of blades continues to increase.

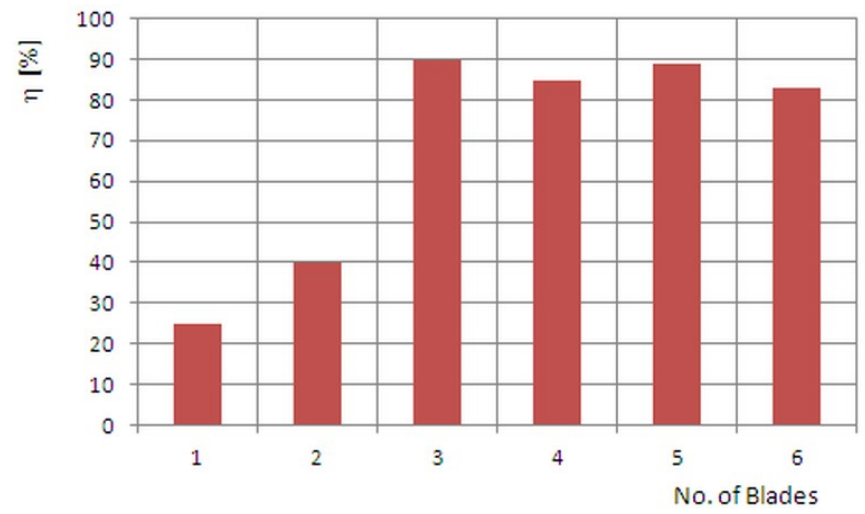

Fig. 9. The relation between turbine efficiency and number of blades

\section{Analysis of results}

Through the analysis resulting from Figures 4 to 9 we notice that there is a linear relationship between flow and mechanical power, with increasing flow increases and mechanical power. The efficiency of the turbine in relation to the flow does not necessarily increase in direct proportion to the increase of the flow, as can be seen from the efficiency curve as a function of flow (Figure 4). The efficiency of the turbine increases to a point where its value is maximum then begins to decrease, the reason for this decrease is due to the higher flow than the nominal flow of the turbine. The excess flow can no longer be transformed into mechanical energy.

The flow rate varies depending on the variation of the inclination angle of the turbine shaft $\left(30^{\circ}, 35^{\circ}, 40^{\circ}, 45^{\circ}\right)$. It can be seen that as the flow rate increases, the rotational speed increases with the increase of the inclination angle of the turbine shaft, but if the inclination angle of the turbine shaft continues to increase, the relationship of the lines of rotation speed converges with the flow rate. This indicates that there is no need for an increase in the value of the angle of inclination of the turbine shaft because it gives the same value of the rotational speed (we get the same mechanical energy but with higher losses). The 
optimal inclination angle of the turbine shaft is $35^{\circ}$. For this value of the angle the maximum value of the turbine efficiency is obtained.

From Figure 7, an increase in rotational speed can be observed with increasing flow. However, the efficiency of the turbine increases until it reaches a maximum value $(80.2 \%$ for an angle of inclination of $35^{\circ}$ ) and then it begins to decrease after reaching the optimum flow, due to the losses caused by the overflow.

In case of variation of torque and efficiency with the number of blades, it is observed that both torque and turbine efficiency increase with increasing number of blades due to increasing contact area between water and blades, but with the continuous increase in number of blades there is a convergence of the values of torque and turbine efficiency, which means that there is no need for an increase in the number of blades, because the torque and efficiency of the turbine have the same values, and increasing the number of blades means manufacturing difficulties but also an increase in costs.

\section{Implementation of screw turbines at a small hydropower plant}

\subsection{Advantages of screw turbine implementation}

Following the research carried out in recent years, it has been found that the implementation of such screw turbines at a small hydropower plant (SHPP), can bring many more benefits than in the case of other types of turbines like Kaplan, Francis, Propeller or Crossflow.

The installation costs of a hydraulic system with Archimedes screw turbines are much lower compared to those for Kaplan turbines. Following research by British researchers, it was found that a hydraulic turbine system with Archimedes' screw produces 15\% more energy than a Kaplan system and the investment costs $10 \%$ less [4].

The results obtained can be seen in the Table 1 .

Table 1. Results obtained with the Archimedes screw turbine compared to the Kaplan turbine

\begin{tabular}{|l|l|l|}
\hline Criterion / turbine type & Kaplan turbine & Archimedes screw turbine \\
\hline Annual energy generation & $390 \mathrm{MWh}$ & $448 \mathrm{MWh}$ \\
\hline Installed capacity & $95 \mathrm{~kW}$ & $124 \mathrm{~kW}$ \\
\hline The cost of the investment & 414.000 euros & 371.000 euros \\
\hline Cost capital MWh/year & 1.061 euro & 828 euro \\
\hline $\begin{array}{l}\text { Internal rate of return (IRR, } \\
20 \text { years) }\end{array}$ & $5 \%$ & $9 \%$ \\
\hline
\end{tabular}

The data in Table 1 show that screw turbines are much more efficient than Kaplan turbines, both in terms of electricity production, but especially in financial terms, therefore the implementation of such turbines would be recommended as several regions. The costs of such hydropower facilities depend very much on the location of the work and cannot be considered universal, but they come with concrete evidence that such projects should be encouraged.

Archimedes' screw turbines are mainly used for flow rates between $0.1 \mathrm{~m}^{3} / \mathrm{s}$ and 15 $\mathrm{m}^{3} / \mathrm{s}$ and have been shown to be less harmful to fish.

The advantages of implementing screw turbines are:

- Changes in flow or water level in the river do not affect the efficiency of the hydraulic system. 
- Studies have shown that fish do not suffer from the implementation of such a hydraulic system, they can cross from one end to the other of the turbine in maximum safety.

- Due to the screw shape of the turbine and the way it operates, branches or other debris can pass on without affecting the functionality of the system, thus reducing maintenance costs.

- The lifetime of such a system can be up to 40 years.

- They do not have a negative impact on the environment.

- The amortization period of the investment is relatively short.

- Maintenance costs are low.

- The installation time of such a system is short.

- The system is very solid, wear-resistant.

- It fits perfectly into the landscape due to the small size and elegance of the screwdriver mechanism.

- Fossil fuel is saved by capitalizing on the hydropower potential of a river.

\subsection{Example of Archimedes' screw turbines at the Zăvoiul Orbului SHPP}

An example of the implementation of Archimedes screw turbine is the one at Zăvoiul Orbului. Zăvoiul Orbului SHPP has the following characteristics:

- Arrangement execution period: $1985 \div 1988$

- $V_{\text {reservoir }} \approx 12$ mil. $\mathrm{m}^{3}$

- Side dams $\approx 7400 \mathrm{~m}$

- Execution - stage I (cover level)

- $H=4.5 \mathrm{~m}$ (actual NRL)

The Zăvoiul Orbului SHPP has the following uses:

- Dâmboviţa additional flow;

- water supply;

- irrigation.

Description of Zăvoiul Orbului SHPP:

- the hydropower arrangement has 2 low head steps - located on the right bank;

- SHPPs are equipped with Archimedes screw turbines $(2 \times 6)$;

- the arrangement produces basic, semi-peak and peak energy with delivery in the national energy system (NES).

Figure 10 shows the Zăvoiul Orbului SHPP.
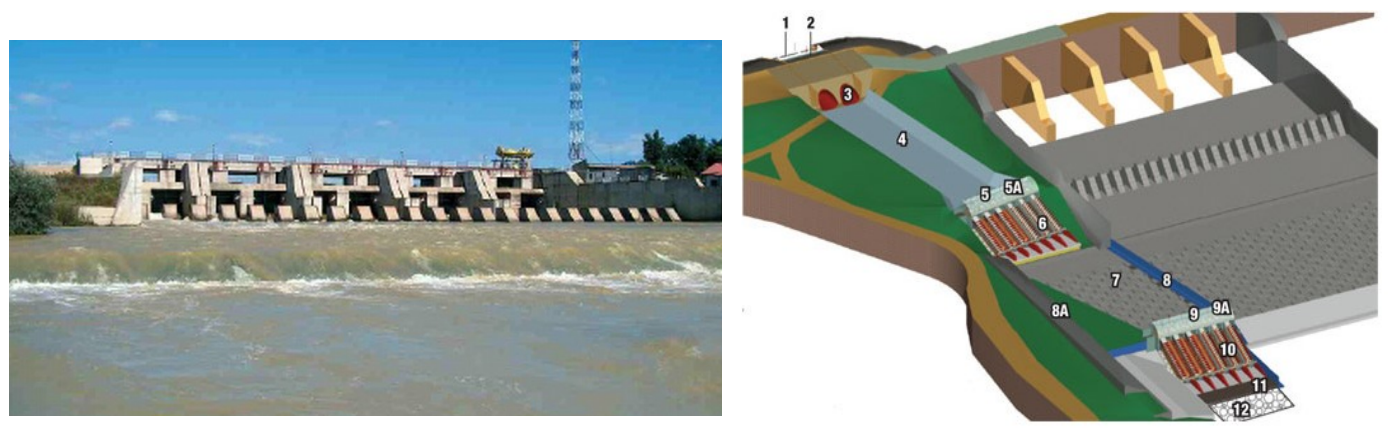

Fig. 10. Overview and principle scheme of the Zăvoiul Orbului SHPP [12] 
Also in Figure 10 we can notice the basic components of the hydropower arrangement: 1 - Water intake, 2 - Manual sluice gates, 3 - Steel culvert, 4 - Headrace channel for SHPP1, 5 - Hydraulically operated sluice gate for first SHPP1, 5A - Electrical equipment for SHPP1, 6 - SHPP1 with six Archimedes screws, 7 - Dissipater acting as headrace channel for SHPP2 screws, 8 - Reinforced concrete wall for mechanical equipment protection, 8A - Reinforced concrete wall, 9 - Hydraulically operated sluice gates in front of SHPP2, 9A - Electric equipment for SHPP2, 10 - SHPP2 screws, 11 - Concrete tailrace, 12 - Gabion mattress foundation.

Zăvoiul Orbului SHHP1 has the following technical characteristics:

Head $\mathrm{H}_{\mathrm{i}} \approx 4.5 \mathrm{~m}$

Installed flow rate $\mathrm{Q}_{\mathrm{i}} \approx 6 \times 6.50 \mathrm{~m}^{3} / \mathrm{s}$

Installed power $\mathrm{P}_{\mathrm{i}} \approx 6 \times 195 \mathrm{~kW}$

Turbines: 6 turbines Archimedes screw

Turbine tilt angle screw $(\alpha) 22^{0}$

Velocity flow $\approx 1.75 \mathrm{~m} / \mathrm{s}$

Figure 11 shows the Zăvoiul Orbului SHHP 1
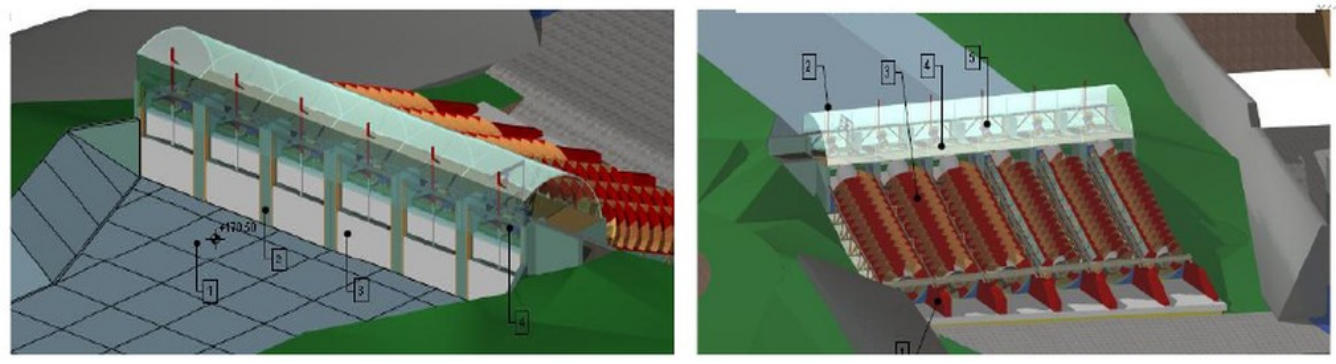

Fig. 11. Zăvoiul Orbului SHHP 1 [12]

Zăvoiul Orbului SHHP 2 has the following technical characteristics:

Head $\mathrm{H}_{\mathrm{i}} \approx 5.2 \mathrm{~m}$

Installed flow rate $\mathrm{Q}_{\mathrm{i}} \approx 6 \times 6.50 \mathrm{~m}^{3} / \mathrm{s}$

Installed power $\mathrm{P}_{\mathrm{i}} \approx 6 \times 220 \mathrm{~kW}$

Turbines: 6 turbines Archimedes screw

Turbine tilt angle screw $(\alpha) 22^{0}$

Velocity flow $\approx 1.75 \mathrm{~m} / \mathrm{s}$

Figure 12 shows the Zăvoiul Orbului SHHP2
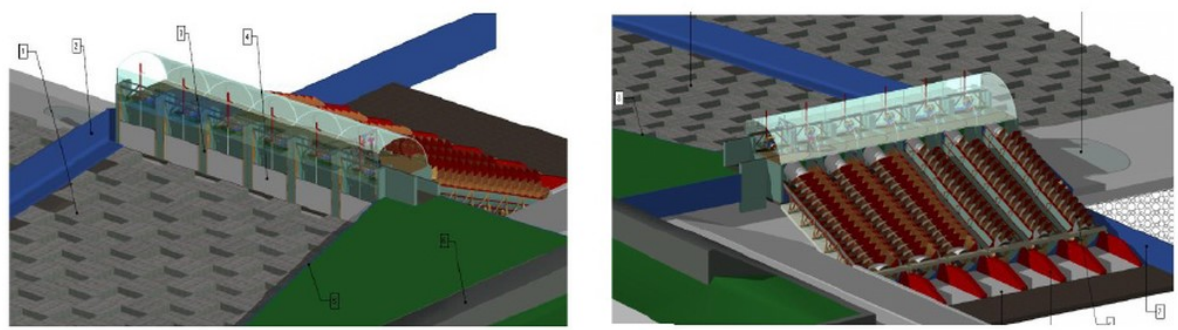

Fig. 12. Zăvoiul Orbului SHHP 2 [12]

The calculation of the energy produced in one year is done with the relationship: 


$$
E_{\mathrm{an}}=P_{\mathrm{i}} \cdot \zeta \cdot T \mathrm{y}
$$

where: $\zeta$ is the utilization coefficient of the SHPP, $\zeta=0,65 \%$ and $T y=8760$ hours $/$ year

For SHPP1 the annual energy produced is: $E_{\mathrm{anSHPP} 1}=6662 \mathrm{MWh}$. For SHPP2 the annual energy produced is: $E_{\text {anSHPP2 }}=7516 \mathrm{MWh}$.

The annual income $V_{\text {an }}$ is:

$$
V_{\text {an }}=E_{\text {an }} \cdot P_{\text {en }}
$$

where $P_{\mathrm{en}}$ is the price of energy and is approximate $100 €$ (we consider the price of one MW of energy of approximately $45 € / \mathrm{MW}$ and a price of the green certificate of 28 $€ / \mathrm{MW})$.

For SHPP1 the annual income is: $728822.8 € /$ year. For SHPP2 the annual income is: $822250.4 € /$ year.

\subsection{Locations for Archimedes' screw turbines}

A possible location where a SHPP equipped with Archimedes' screw turbines can be located can be on the river Argeş, between Zeama-Rece and Catanele as in figure 13.

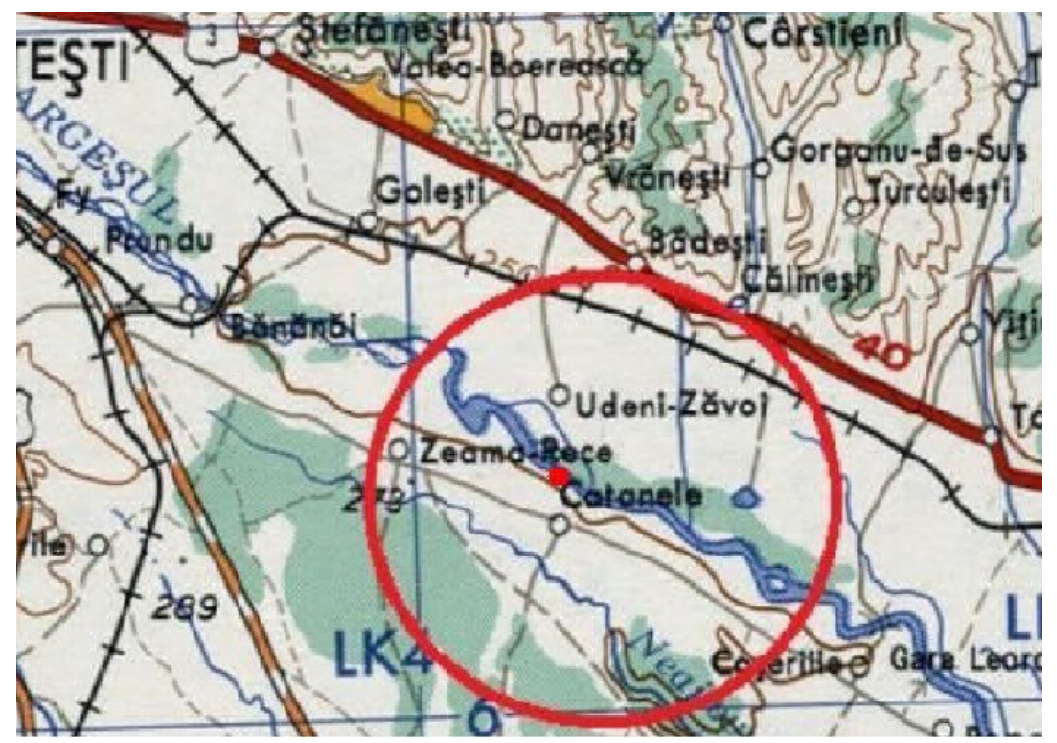

Fig. 13. Possible location for Archimedes' screw turbines

Another possible location for the location of Archimedes' screw turbines could be the irrigation canals. These are one of the best micro-hydropower resources, as they have many energy dissipation structures to reduce the hydraulic energy of flowing water. Some of these structures are the troughs, the settling tank etc., which dissipate excess water energy as heat loss. Excess energy from the water flowing in such structures can be converted into electricity. Given that Archimedes' screw turbines are efficient, fish-friendly, environmentally friendly devices and require little civilian work to implement in existing structures, they could be a good candidate for this purpose. There are also many new hydroelectric systems, including Archimedes' screw turbines that can be used in already existing structures (e.g. non-powered dams) to supply electricity. 


\section{The "fish friendly" character of the screw turbine}

In the case of screw turbines it can be easily demonstrated that due to the slow rotational speed of the screw and the large space through which water passes, all categories of fish, even larger ones, can cross the turbine without suffering [13].

As a result, several environmental protection agencies have announced that it is not necessary to implement a protection screen.

Thousands of fish were monitored and video recordings were made using underwater cameras located both at the entrance to the turbine, inside the chambers through which the water passes, but also at the exit of the hydropower system, to evaluate the effect of the turbine Archimedes screw on some fish species of salmonids class. It was found that no fish were affected, they were crossing safely.

In the Figure 14 are presented fish species unaffected by screw turbines.
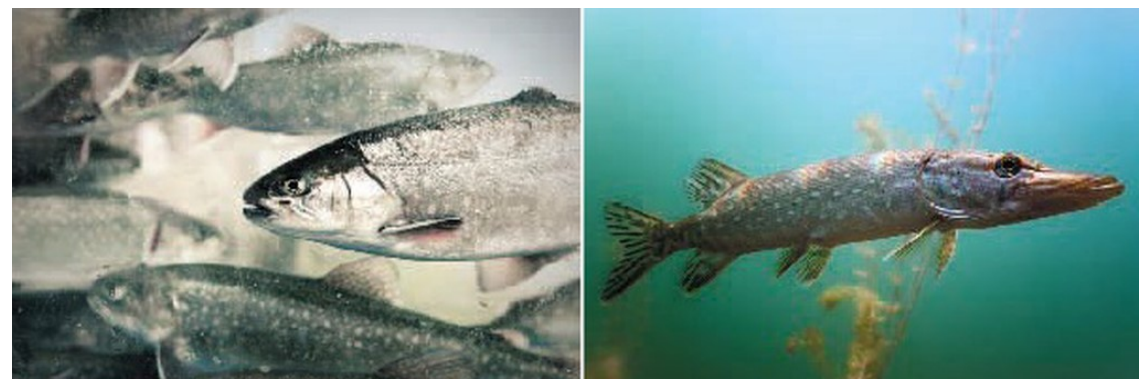

Fig. 14. Fish species unaffected by Archimedes' screw-type turbines [14]

A recent study by VisAdvies at the Hooidonkse Mill on the Dommel River in the Netherlands shows that these Archimende screw turbines are harmless to most fish species [14]. A total of 214 fish were monitored through the turbine. The size of the fish was between $4-15 \mathrm{~cm}$ and no fish was affected, they crossed safely.

Figure 15 shows the fish species that can pass through the screw turbine and the number of unaffected fishs.
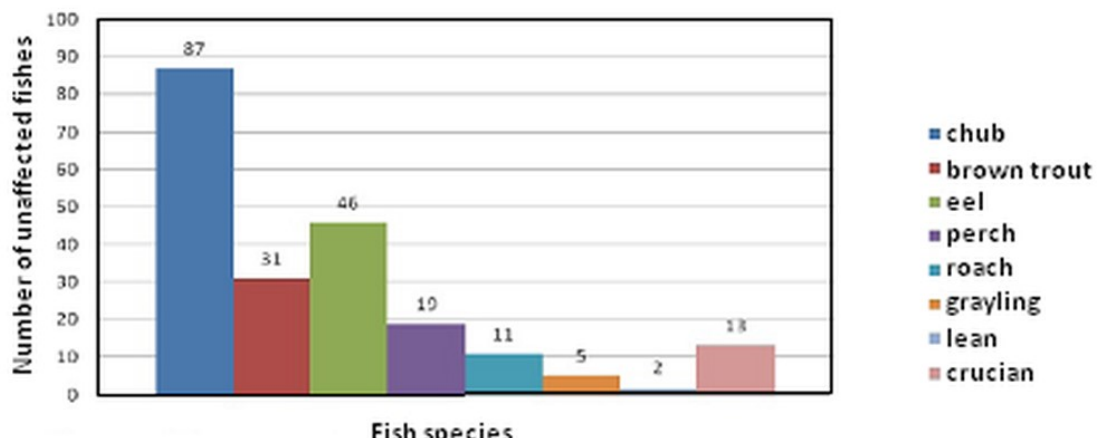

Fish species

Fig. 15. The number of unaffected fishes by the Archimedes screw turbines [14]

\section{Conclusions}

As the world begins to understand the dangers of global warming, green energy is generating more and more interest. It is useful to look back at the great engineers of the past 
who first exploited the earth's natural energy, green/renewable energy. With a few design changes it can switch from screw pump to turbine screw. Archimedes screw turbine offers a lot of advantages over today's adjustable turbines. The lack of environmental effects, combined with a wide range of location possibilities as well as the robust, trouble-free nature of the screw turbine design, make this turbine offer sustainable renewable energy solutions for many locations.

Locations such as irrigation canals, or various existing energy structures could be used to locate Archimedes' screw turbines, e.g. non-powered dams. Archimedes' screw turbines can be successfully placed on different rivers, e.g. Argeş river between the localities Zeama-Rece and Catanele.

The implementation of Archimedes' screw turbines brings many more benefits than the implementation of other types of turbines, Kaplan, Francis, Propeller, Crossflow. According to the literature, the installation costs of a SHPP with Archimedes screw turbines are much lower compared to those for installing Kaplan turbines. At the same time, it was found that an Archimedes screw turbine hydraulic system produces 15\% more energy than a Kaplan system and the investment costs $10 \%$ less.

Among the benefits of Archimedes turbines can be mentioned: the flat efficiency curve, which means that even dramatic changes in flow or fall do not significantly affect the efficiency of the system, high mechanical efficiency $85 \%$. They can operate up to a flow rate of $5 \%$ of the design flow, are fish friendly turbines (many studies have been conducted and it has been shown that fish do not suffer any damage when crossing through the turbine Archimedes screw, in fact Archimedes screws are used in some areas as pumps to move fish from one basin to another), they have tolerance to dirty water due to their design and mode of operation, are robust due to their simple construction and no complex control/automation system is required.

Although remarkable progress has been made in recent years in the theoretical and practical study of Archimedes' screw turbines still further researches are needed to be able to optimize the design for the different ways of placing the turbine (sunken, inclined or horizontal), because each method generates electricity in a different way. Much of current design theory is based on pump design, not turbine design. Many of the design criteria can be used for any of them; however, there are key differences in operation, such as the direction in which water passes through the turbine.

\section{Acknowledgments}

This paper has been financed from the Nucleus Program funds that has been carried out with the support of the MEC project no. PN 19400401 contract MCI no. 27N /2019.

\section{References}

1. K. Kusakana, J. Munda, A. Jimoh, Economic and environmental analysis of micro hydropower system for rural power supply, Power and Energy Conference, 2008. PEC on 2008, IEEE $2^{\text {nd }}$ International, pp. 441-444. IEEE, (2008)

2. J. Du, H. Yang, Z. Shen, J. Chen, Micro hydro power generation from water supply system in high rise buildings using pump as turbines, Energy 137 (2017), pp.431-440.

3. A. Kozyn, S. Ash, W. Lubitz, Assessment of archimedes screw power generation potential in Ontario, CCTC 2015, paper number 1570095585, in: Climate Change Technology Conference, Montreal (2015). 
4. REN21, Renewables 2012: Global Status Report, Renewable Energy Policy Network for the $21^{\text {st }}$ Century, (2012).

5. L. Lisdiyanti, Y. Hizhar, B. Yulistiyanto, Effect of Flow Discharge and Shaft Slope of Archimides (Screw) Turbin on the Micro-hydro Power Plant, (2012).

6. K. Kashyap, R. Thakur, S. Kumar, Identification of Archimedes Screw Turbine for Efficient Conversion of Traditional Water Mills (Gharats) into Micro Hydro-power Stations in Western Himalayan Regions of India: An Experimental Analysis.INTERNATIONAL JOURNAL of RENEWABLE ENERGY RESEARCH, Vol.10, No.3, (2020).

7. K. Brada, Hydraulic screw generates electricity from micro hydropower stations. Maschinenmarkt Würzburg, Mitteilung 14, pp.52-56, (1999).

8. S. C. Georgescu, A. M. Gorgescu, Hydraulics of pipelines and hydraulic machines. Editura PRINTECH, (2007).

9. U. Kumar, P. Singh, A. C. Tiwari, Suitability of Archimedes Screws for Micro Hydro Power Generation in India. International Journal of Thermal Technologies, Vol. 6, No. 3, pp. 273-278, (2016).

10. O.S. Abdullah, A.H. Kamel, W.H. Khalil, Numerical and Experimental Modelling of Small Hydropower Turbine. Journal of Engineering and Applied Sciences, Vol. 15, No. 20, pp. 2244-2250 (2020).

11.S. Simmons, A Computational Fluid Dynamic Analysis of Archimedes Screw Generators. Presented to The University of Guelph In partial fulfilment of requirements for the degree of Master of Applied Sciences in Engineering Guelph, Ontario, Canada. (2018).

12.*** https://www.hydroreview.com/world-regions/adding-hydro-to-a-non-powered-damin-romania

13. A. YoosefDoost, W.D. Lubitz, Archimedes Screw Turbines: A Sustainable Development Solution for Green and Renewable Energy Generation-A Review of Potential and Design Procedures. Sustainability, 12, No (18) 7352; doi:10.3390/su12187352, (2020).

14. *** http://www.ecoevolution.ie 